\title{
Finding the Right Questions
}

by Steve Bourne, Chair, Queue Advisory Board

D oes the world really need another computing magazine? Surely, that's a legitimate question. By any measure, we already have an overwhelming number of publications to choose from. But how many do you actually read? And of those, how many do you feel really contribute to your knowledge and understanding of emerging software technologies and capabilities?

Sadly, even amongst the more serious and sober-minded of all those publications out there, there is little that looks potentially useful to people charged with anticipating and preparing for future challenges. That's because the tendency is more towards content grounded in the here-and-now, with an emphasis on products and solutions already familiar to programmers and developers.

So into the clutter now steps a new publication: Queue. Quite simply, it's not like any of those other magazines piling up on your office floor. That's because the mission for Queue is to deal directly with the challenges ahead for software engineers and developers involved in the critical design and planning decisions most likely to affect product directions and operational practices for years to come. And when it comes to that, articles that merely describe current products and solutions are inadequate. So Queue instead sets out to intelligently assess the changes expected to arise in the near term as emerging capabilities or technologies gain widespread acceptance-laying out the choices software engineers and developers are most likely to face and spelling out the inherent underlying technical conflicts.

Unlike the other magazines I've seen, Queue understands that before people can begin to search for satisfactory answers, they must first know what questions to ask. Other publications may devote themselves to touting the latest panacea du jour. But Queue has been conceived largely as a tonic for the hype weary, with a commitment to methodically dissect upcoming challenges while posing the same hard questions software developers ask themselves. And in that way, Queue works to define future problems with the sort of detail and intelligence readers

\section{Before people can}

begin TO SEARCH FOR SATISFACTORY ANSWERS, THEY MUST FIRST KNOW WHAT QUESTIONS TO ASK. coming. Queue has the ability to do that because it's built out of editorial content driven and written by engineers. An editorial advisory board consisting of industry luminaries who meet regularly to discuss article ideas and identify potential authors makes it possible to secure material from people with the real experience and technical savvy to write with real authority on their respective topics.

I think you'll agree that doesn't sound much like any of those other magazines you've been reading lately. $Q$

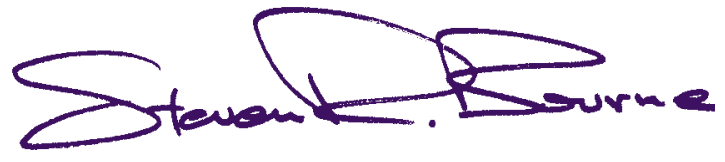

STEVE BOURNE has held senior engineering management positions at leading computer systems and networking companies including Cicso, Sun Microsystems, Digital Equipment and Silicon Graphics. At present he is Entrepreneur in Residence at El Dorado Ventures in Menlo Park. Steve is well known for his work on the UNIX operating system and designed the UNIX Command Language or "Bourne Shell". 